\title{
AFINAL, QUEM DEVE SER O GUARDIÃO DA CONSTITUIÇÃO?
}

Valterlei A. da Costa*

\section{RESUMO:}

O presente artigo investigar as formas de garantia da Constituição, especialmente no que diz respeito à constitucionalidade das leis, tomando, como ponto de partida, uma teoria que permite classificar as normas jurídicas, por um lado, em norma primária e secundária e, por outro lado, em norma de conduta e competência. Então, dentro da teoria normativa adotada, demarca o significado de "controle de constitucionalidade" e passa a perquirir sua necessidade, haja vista a imperiosidade de eficácia dos dispositivos constitucionais como condição de validade, bem como qual o órgão mais adequado para o exercer, tendo por referência os valores democráticos.

PALAVRAS-CHAVES: constituição; democracia; controle de constitucionalidade; Hans Kelsen; Carl Schmitt.

\section{AFTER ALL, WHO SHOULD BE THE GUARDIAN OF THE CONSTITUTION?}

\begin{abstract}
:
This paper is a research about the guarantees of the Constitution, especially on the constitutionality of laws, through of a theory that allows to classify the legal norms, on the one hand, in primary norm and eventual norm and, on the other hand, in norm of conduct and norm of competence. Then establishes the meaning of constitutional review, within the normative theory adopted, and inquire about its need, due to the imperiousness of the effectiveness of constitutional provisions as a condition of validity, as well as the institution most appropriate to perform it, with reference to democratic values.
\end{abstract}

KEYWORDS: constitution; democracy; constitutional review; Hans Kelsen; Carl Schmitt.

\section{INTRODUÇÃO}

Se tivermos a Constituição da Áustria como marco, há 100 anos vem se discutindo, com base no direito positivo, a necessidade, e a melhor forma, de se ter um guardião da Constituição $^{1}$; contagem que, todavia, vai há mais de 200 anos se deslocarmos o marco inicial para a decisão da Suprema Corte Americana, no clássico caso "Marbury versus Madison", de

\footnotetext{
* Mestre e Bacharel em Direito pela UFPR. Ex-Técnico de Finanças e Controle da Procuradoria da Fazenda Nacional. Membro do Instituto de Direito Tributário do Paraná. Professor dos cursos de pós-graduação em direito lato sensu da UNICURITIBA e ABDCONST. Advogado em Curitiba/PR. E-mail: costa.valterlei@gmail.com.

1 “Antes de entrar em vigor a Constituição de 1920, republicana e federativa, os tribunais austríacos [...] só podiam controlar a constitucionalidade das leis no tocante à sua adequada publicação, vale dizer, tendo em vista sua existência, mas jamais sua validade em fazer do texto constitucional”. (CUNHA, 2013, p. XII).
} 
$1803^{2}$. De toda sorte, tomaremos neste artigo, como marco teórico do tema, seu ponto alto, o debate entre $\mathrm{KELSEN}^{3}$ e $\mathrm{SCHMITT}^{4}$, para, então, concluir que as posições desses dois grandes juristas, que são apresentadas como antípodas, na verdade, têm muito em comum. Antes, no entanto, devemos expor como o tema do controle de constitucionalidade das leis é compreendida dentro uma teoria estruturalista do direito, para que se possa, a partir disso, investigar quem deve ser, afinal, o guardião da Constituição.

\section{CONSTITUIÇÃO FORMAL}

Uma das mais conhecidas conceituações de Constituição é a que lhe atribui, por um lado, o significado de uma mera folha de papel, contrapondo-lhe o poder real, que seria a verdadeira Constituição ${ }^{5}$. Por essa linha, não se conheceria a Constituição de um Estado lendo seu Texto Primeiro, devendo, ainda, ser buscadas as forças reais e efetivas de poder. De nossa parte, entendemos que tal estudo, a partir de uma posição de especialização do conhecimento - o que, diga-se, está fora de moda, já que vivemos época em que a palavra mote é o substantivo "disciplinaridade" acompanhada de algum prefixo ${ }^{6}-$, seria mais bem conduzido pela sociologia.

Ademais, sobre a relação entre norma e fato, é interessante notar que mesmo um autor como HESSE (1991, p. 28) — o qual não cede à ideia de que ou a Constituição reflete os poderes reais ou, então, não é nada - expõe que “[...] a força normativa da Constituição

\footnotetext{
2 “"...] la Justicia Constitucional, tal y como fue configurada por Kelsen, estableciendo un modelo diferente de control de constitucionalidad al consagrado en la tradición americana, a partir de 1803, por el juez Marshall en el caso Marbury versus Madison". (GARCÍA, 1998, p. 19).

${ }^{3}$ Quanto a KELSEN, dono de uma obra vastíssima, em uma vida longa a serviço da ciência do direito, destacamos um artigo de 1928, publicado, inicialmente, em francês, e só depois em alemão, "La garantie jurisdictionelle de la Constitution (La justice constitutionelle), na Revue de droit public et Science politique, 35/197-257, cuja tradução para o português coube a Maria Ermantina Galvão, sob o título "A jurisdição constitucional", e outro de 1930, "Wer soll der Hüter der Verfassung sein?", publicado em Die Justiz. 1930-31, Heft 11-12, Band VI, Seite 576628 , traduzido para o português por Alexandre Krug, e nominado de "Quem deve ser o guardião da Constituição?".

${ }^{4}$ A conhecida obra de SCHMITT "A defesa da Constituição" é uma ampliação de dois trabalhos publicados anteriormente: "Das Reichsgericht als Hüter der Verfassung", publicado em Die Reichsgerichtspraxis im deutschen Rechtsleben, Berlin, 1929, e "Der Hüter der Verfassung", em Beiträge zum öffentlichen Recht der Gegenwart, Tübingen, 1931.

5 "Os problemas constitucionais não são problemas de direito, mas de poder, a verdadeira Constituição de um país somente tem por base os fatores reais e efetivos do poder que naquele país regem, e as constituições escritas não têm valor nem são duráveis a não ser que exprimam fielmente os fatores do poder que imperam na realidade social [...]". (LASSALE, 2016, p. 57).

${ }^{6}$ Não temos interesse em promover um debate sobre os novos significados que o termo "disciplina" ganha quando acoplado aos prefixos "pluri”, "multi”, "inter" e "trans". Deixamos tal pesquisa aos militantes da área.
} 
depende da satisfação de determinados pressupostos atinentes à práxis e ao conteúdo da Constituição". Nesse ponto, com base em KELSEN, podemos estabelecer que um mínimo de eficácia é condição de validade do ordenamento jurídico ${ }^{7}$. Isso, por sua vez, não reduz o deverser ao ser, o que causaria horror a $\mathrm{HUME}^{8}$, mas estabelece uma ponte entre os mundos, mesmo que com o perdão pela quebra da pureza metodológica. Todavia, neste trabalho, não precisamos ir tão longe, perscrutando se haveria um fundamento normativo detrás da Constituição, bastando-nos que a tomemos como fonte primeira das normas jurídicas.

Se permitirmo-nos deixar de lado o costume, podemos, então, estabelecer, aqui, a Constituição como texto, o qual, uma vez interpretado, oferta-nos as normas jurídicas constitucionais, as quais, em razão de serem dotadas de um mínimo de eficácia, modificam o mundo. Agora, com essa pequena exposição, vemos deslocada a questão da constitucionalidade para o significado da expressão "norma jurídica". Sem nos desviar do tema deste artigo, sumariamente podemos cuidar do assunto por meio de uma sóbria classificação, pela qual as normas jurídicas podem ser estudadas de um ponto de vista estático ou dinâmico.

Estaticamente, pode-se tomar, não sem risco de não se conseguir explicar a função promocional, a posição de que o direito é um conjunto de normas jurídicas homogêneas do ponto de vista sintático, cambiando apenas em relação ao conteúdo. De toda sorte, adotamos aqui serem as normas jurídicas, todas elas, o que incluem as normas constitucionais, formadas por duas partes. Assim, “[p]or variado que seja estilisticamente, tecnicamente, idiomaticamente, o modo como o direito positivo de uma sociedade concreta se exprime, onde há regras [...], aí encontramos sua composição dual”. (VILANOVA, 2005, p. 82). No entanto, isso ainda diz pouco sobre a norma jurídica, pois, em mais detalhes, ela não é meramente bimembre, mas apresenta uma dupla estrutura condicional, cuja nomenclatura é variada na

\footnotetext{
${ }^{7}$ Não pretendemos discutir aqui se o mínimo de eficácia se aplica a cada norma jurídica em particular ou à ordem jurídica de forma global. KELSEN $(1998$, p. 12) é da posição de que uma norma ineficaz, mesmo pertencendo a uma ordem eficaz, deixa de ter validade: "Uma norma que nunca e em parte alguma é aplicada e respeitada, isto é, uma norma que [...] não é eficaz em uma certa medida, não será considerada como norma válida (vigente). Um mínimo de eficácia [...] é a condição de sua vigência".

${ }^{8}$ É conhecida por "lei de Hume" a impossibilidade de se deduzir o que deve ser (ought) do que é (is): "Em todo sistema de moral que até hoje encontrei, sempre notei que o autor segue durante algum tempo o modo comum de raciocinar, estabelecendo a existência de Deus, ou fazendo observações a respeito dos assuntos humanos, quando, de repente, surpreendo-me ao ver que, em vez das cópulas proposicionais usuais, como é e não é, não encontro uma só proposição que não seja conectada a outra por um deve ou não deve. Essa mudança é imperceptível, porém da maior importância. Pois, como esse deve ou não deve expressa uma nova relação ou afirmação, esta precisaria ser notada e explicada; ao mesmo tempo, seria preciso que se desse uma razão para algo que parece inteiramente inconcebível, ou seja, como essa nova relação pode ser deduzida de outras inteiramente diferentes". (HUME, 2009, p. 509).
} 
doutrina, mas que, de qualquer forma, contém, além da conduta devida se ocorrida a hipótese, também a consequência em caso de descumprimento da conduta devida 9 .

Dinamicamente, por sua vez, norma jurídica é aquela que tem seu fundamento de validade em outra norma jurídica. Sendo assim, há uma conduta humana, a ação normativa ${ }^{10}$, que assenta certa norma jurídica, mas tal conduta somente é lida como criadora de direito porque uma outra norma jurídica assim estabelece, a qual denominamos de norma de competência $^{11}$. Como a norma de competência é direito positivo, é norma posta, isso implica a existência de uma outra ação normativa que a pôs, o que, prosseguindo com o raciocínio, leva a compreensão de que essa última ação somente pode ser uma ação normativa se assim também dispuser uma outra norma jurídica, sua fonte de validade. E nisso há um regresso ad infinitum.

Uma tentativa de resolver o impasse — e, sem dúvidas, um dos temas mais polêmicos da teoria kelseniana ${ }^{12}$ - é por meio da norma fundamental, quando, então, teríamos uma norma pressuposta como validade das normas $\operatorname{postas}^{13}$. Não precisamos aqui, neste trabalho, adentrar em tal seara, bastando estabelecer que o direito é uma construção escalonada, o que nos leva a entender a Constituição como o conjunto primário de normas jurídicas, que são postas pelo fato fundamental ${ }^{14}$, a ação normativa primeva, a qual ocupa o topo da pirâmide ${ }^{15}$.

\footnotetext{
${ }^{9}$ COSSIO (2007, p. 122) usa endonorma e perinorma: "La prestación es lo que debe ser según la endonorma, pero según la perinorma es la sanción lo que debe ser". KELSEN empregou, tanto na $1^{\mathrm{a}}$, como na $2^{\mathrm{a}}$ edição da "Teoria Pura do Direito", norma primária para a que estabelece a conduta devida e norma secundária para a que dispõe sobre a sanção. Todavia, em livro de publicação póstuma, "Teoria Geral das Normas", cambiou a nomenclatura: "Se se admite que a distinção de uma norma que prescreve uma conduta determinada e de uma norma que prescreve uma sanção para o fato da violação da primeira seja essencial para o Direito, então precisa-se qualificar a primeira como norma primária e a segunda com secundária - e não o contrário, como o foi por mim anteriormente formulado". (KELSEN, 1986, p. 181). De nossa parte, falamos em norma primaria e norma eventual: "Uma norma jurídica prescreve a " $\mathrm{S}_{1}$ " primeiramente uma conduta, de forma condicional. Por causa disso, vamos chamá-la de "norma primária". Uma outra norma jurídica também prescreve conduta, só que agora, a " $\mathrm{S}_{2}$ ", mas só eventualmente, ou seja, somente se não se der a primeira conduta. Por isso, vamos chamá-la de "norma eventual". (COSTA, 2019, p. 46).

10 "Para el modo peculiar de la acción, que tiene como resultado la existencia de prescripciones, acuñamos el nombre acción normativa". (VON WRIGHT, 1970, p. 91-92).

11 "As normas jurídicas podem ser divididas, de acordo com seu conteúdo imediato, em dois grupos: normas de conduta e normas de competência. Ao primeiro grupo pertencem as normas que prescrevem uma certa linha de ação [...]. O segundo grupo contém as normas que criam uma competência (poder, autoridade) — são diretivas que dispõem que as normas que são criadas em conformidade com um modo estabelecido de procedimento serão consideradas como normas de conduta". (ROSS, 2003, p. 57).

12 "A polêmica concentra-se em quatro pontos: a necessidade, a possibilidade, o conteúdo e o status da norma fundamental". (ALEXY, 2009, 117).

13 " [...] sob a condição de pressupormos a norma fundamental: devemos conduzir-nos como a Constituição prescreve, quer dizer, de harmonia com o sentido subjetivo do ato de vontade constituinte, de harmonia com as prescrições do autor da Constituição". (KELSEN, 1998, p. 225).

${ }^{14}$ Sobre o "fato fundamental", ensina-nos VILANOVA (1981, p. 84): "Não é a norma fundamental que produz ou traz ao nível da existência, o fato fundamental. Ao contrário, dado o fato fundamental, para colhê-lo em termos de
} 
Não é, assim, o particular conteúdo da norma jurídica que faz dela uma norma constitucional, uma vez que ela, nos termos de KELSEN (1998, p. 248), “[...] pode assumir qualquer conteúdo [...]", mas sim o fato de não buscar sua validade em nenhuma outra norma jurídica. Com efeito, se o direito é uma estrutura escalonada, então “[...] a Constituição representa o escalão de Direito positivo mais elevado". (Ibidem, p. 247). Adotamos, aqui, como síntese, um conceito formal de Constituição, sendo as normas constitucionais as que concedem validade a outras normas jurídicas, mas que não busca, ela mesma, sua validade em nenhuma outra norma jurídica.

\section{CONSTITUIÇÃO MATERIAL}

Se a tomada de posição é pela homogeneidade sintática das normas jurídicas, então uma classificação das normas jurídicas como de conduta e de competência somente tem lugar por meio da semântica, ou seja, é o conteúdo que permite assim determinar. Logo, normas de competência são aquelas que disciplinam a conduta que cria, altera ou exclui uma outra norma jurídica, o que não deixa de fazer delas também normas de conduta, só que extremamente específicas, pois “[...] o comportamento que elas regulam é o de produzir regras” (BOBBIO, 1999, p. 45).

Com isso, é de se entender que a Constituição seja o lugar primeiro para as normas de competência - mas não único — , o que nos leva a falar, nesse caso, de Constituição material, a qual "[...] consiste nas regras que regulam a criação das normas jurídicas gerais, em particular a criação de estatutos”. (KELSEN, 2005, p. 182). Assim, toda Constituição material é também Constituição formal, mas nem toda Constituição formal é Constituição Material. Ademais, ao regular o processo de criação do direito, a Constituição material não determina somente a forma de produção, como também a temática. Com efeito, “[a] constituição material determina não apenas os órgãos e o processo de legislação, mas também, em certo grau, o conteúdo de

conhecimento dogmático, pressupõe-se a norma que lhe corresponde, põe-se a hipótese normativa básica que tem o fato fundamental por conteúdo".

${ }^{15}$ KELSEN adotou de seu aluno MERKL a ideia de que o direito é uma construção em nível (Stufenbau), conforme nos relata o grande conhecedor da obra kelseniana WALTER (2013, p. 50).: "Nos hauptproblemen der Staatsrechtslehre (Problemas Principais da Teoria Jurídica-Estatal, 1911) fundamento da Teoria Pura do Direito, Kelsen se concentra, por completo, na análise das leis. A elaboração das leis e a execução das leis permanecem, conscientemente, excluídas. A obra foi dedicada, portanto, a uma consideração estática do direito. Isso mudou, porém sob a influência do discípulo de Kelsen, Adolf Merkl (1890-1970). No prólogo da segunda edição (não modificada) dos Hauptproblemen (1923), Kelsen escreveu sobre o desenvolvimento da doutrina, afirmando que havia 'tomado a teoria do escalonamento como parte essencial no sistema da Teoria Pura do Direito". 
futuras leis". (KELSEN, 2005, p. 249). São essas determinações de conteúdo o que chamamos de Carta de Direitos ${ }^{16}$.

A existência de uma Carta de Direitos faz com que a Constituição, ao dispor sobre o conteúdo da legislação, opte por um de dois caminhos: ou os expressa positiva ou negativamente, sendo ainda legítima uma combinação de ambos. Apesar disso, se lembrarmos que os modos de conduta, ao menos o proibido e o obrigado, apesar de não serem redutíveis um ao outro, são interdefiníveis, a questão perde importância do ponto de vista sintático, pois uma sentença como "é obrigatório tratar todos igualmente" pode ser escrita como "é proibido tratar alguém não igualmente". Todavia, no plano pragmático, a forma como se usa a linguagem importa, mas isso é ponto que deixaremos aqui de desenvolver.

De todo modo, qualquer que seja a forma linguística, para que não seja uma mera recomendação, é necessário que a Constituição tenha um processo de modificação de suas normas diverso, mais custoso, do que aquele que estabeleceu para a positivação da legislação comum $^{17}$. Isso porque, se assim não for, pela aplicação do dispositivo lex posterior derogat priori, sem aqui discutirmos se ele deve ser positivado no sistema ou pode ser simplesmente derivado, a norma que, prima facie, poderia ser tido como em desacordo com a Constituição, na verdade, estaria revogando-a e não com ela sendo incompatível. Assim, é o caso de compreendemos como presente, para que se possa falar de controle de constitucionalidade, sem novamente discutirmos sobre sua positivação ou derivação, o dispositivo lex posteriori inferior non derogat priori superiori.

Com a Constituição estabelecendo um procedimento e um conteúdo para as normas jurídicas que serão postas, as quais terão supedâneo nela, então não é possível descartar a possibilidade de o legislador agir em desconformidade com o estabelecido, pois "[s]e os homens fossem anjos, não haveria necessidade de governo: e se anjos governassem os homens não haveria necessidade de meio algum externo ou interno para regular a marcha do governo

\footnotetext{
${ }^{16}$ Qual é o conteúdo mínimo de uma Carta de Direitos? DAHL (2015, p. 26) diz-nos que “[...] todos os cidadãos plenos devem ter oportunidades plenas: 1. De formular suas preferências. 2. De expressar suas preferências a seus concidadãos e ao governo através da ação individual e da coletiva. 3. De ter suas preferências igualmente consideradas na conduta do governo [...]. Essas me parecem as três condições necessárias à democracia, ainda que, provavelmente, não sejam suficientes". Para, logo à frente, expor que "[a]s poliarquias podem ser pensadas [...] como regimes relativamente (mas incompletamente) democratizados, ou, em outros termos, as poliarquias são regimes que foram substancialmente popularizados e liberalizados, isto é, fortemente inclusivos e amplamente abertos à contestação pública". (Ibidem, p. 31).

17 "Se existe uma forma constitucional, então as leis constitucionais devem ser distinguidas das leis ordinárias. A diferença consiste em que a criação, isto é, decretação, emenda, revogação, de leis constitucionais, é mais difícil que a de leis ordinárias”. (KELSEN, 2005, p. 182).
} 
[...]". (HAMILTON ou MADISON, 1979, p. 131) ${ }^{18}$. O que não leva, depois de demarcado que do texto constitucional se obtém normas de competência, a um segundo ponto, qual seja: que consequências devem advir do descumprimento das normas de competência?

\section{NORMA DE GARANTIA}

Sintaticamente, ponto ora adotado, todas as normas jurídicas são idênticas, nos termos do princípio da homogeneidade, o que nos leva a questionar, para as normas de competência, qual norma se liga a ela para formar o duplo par "antecedente imputado ao consequente" norma jurídica completa —, mas deixamos, todavia, para mantermo-nos no espoco deste artigo, de analisar qual sincategorema os conecta. De forma geral, é dito que a segunda parte da norma jurídica completa é uma norma sancionadora, mas conforme exposto acima, preferimos norma eventual, pois com isso evitamos ideias associativas que o termo sanção possa provocar, com a referência a um mal, e focamo-nos em ser essa segunda norma, na verdade, essa segunda parte da norma completa, uma consequência em razão do descumprimento da conduta devida. Isso é de fundamental importância, pois deixamos de ter de explicar por que a invalidação, quando apresentada como norma sancionadora, corresponderia a um mal e restringimo-nos a dizer, sem valoração, que é meramente uma consequência ${ }^{19}$.

De todo modo, a norma de competência, obtida da Constituição material, pode ser descumprida pelo legislador no exercício de sua função. Como primeiro impulso, poderia ser negada à norma posta em contrariedade com a norma que lhe concede validade a própria existência. Entretanto, tal posicionamento não é realista, pois as normas assentadas em desconformidade com certo procedimento ou mesmo contrárias ao conteúdo pré-estabelecido pela Constituição (positiva ou negativamente) são ainda assim válidas, bastando, para isso

\footnotetext{
${ }^{18}$ MORESO (1997, p. 88), sobre as normas não serem descumpridas, diz que isso somente é possível em um "mundo jurídico ótimo" (MJO): "En MJO, el poder legislativo sólo dicta leyes de acuerdo a la constitución, el poder ejecutivo sólo dicta reglamentos autorizados por las leyes [...] y el poder judicial [...] sólo dicta sentencias [...] de acuerdo y conforme a las normas válidas. En MJO no hacen falta mecanismos como el control de constitucionalidad o la apelación de sentencias".

19 "Temos duas normas jurídicas, com mesma estrutura, mas diversas no conteúdo, como também endereçadas a pessoas diferentes. Em relação à norma primária, para a hipótese, fixamos qualquer conteúdo desde que a facticidade seja possível; já a consequência, respeitado o limite empírico, deve ser ela uma conduta humana. Nossa sintaxe da norma jurídica vem acompanhada de conteúdo mínimo. No que tange à segunda norma jurídica, sua hipótese sempre será a não ocorrência da conduta devida, e a consequência, será uma conduta, devida apenas na eventualidade, sem que precisemos entrar em discussões sobre se há nela questões como dor e prazer e como alguém disso se apercebe. Abre-se, assim, o guarda-chuva. Sob a denominação de eventualidade, cabe agora qualquer conteúdo para a conduta: pena, prêmio, inconstitucionalidade, ilegalidade, anulabilidade etc". (COSTA, 2019, p. 46).
} 
constatar, deixar de lado a questão meramente conceitual e focar-se na eficácia ${ }^{20}$. Sendo assim, as normas assentadas como fruto do exercício de competência constitucional, mesmo que em desconformidade com a forma ou conteúdo, são válidas prima facie.

O foco, portanto, é estabelecer, por meio de norma eventual, as consequências para o descumprimento de norma de competência presente na Constituição material, o que pode ser feito de duas maneiras, sem serem elas excludentes: responsabilização da autoridade que pôs a norma; ou invalidação da norma posta ${ }^{21}$. Para este último caso, os efeitos da invalidação podem ser ou ex nunc ou ex tunc ${ }^{22}$. E é nesse ponto, então, que tem lugar a questão objeto deste artigo: quem deve ser o guardião da Constituição?

As normas de competência presentes na Constituição material são endereçadas ao legislador, que, em uma democracia, não pode ser outro que não o parlamento. Entretanto, com isso não é possível afastar a possibilidade de que, ao instituir o direito (ou alterá-lo ou excluilo), não haja ele de acordo com o prescrito, não respeitando a forma ou o conteúdo dispostos constitucionalmente. Para tanto, para que o direito tenha um mínimo de eficácia, é necessário a presença de uma norma eventual, acoplada à norma de competência, estabelecendo consequências para seu descumprimento. Vamos aqui, delimitando o objeto deste escrito, deixar de lado a responsabilização pessoal e focarmo-nos na invalidação da norma posta, o que nos permite expor, tomando a norma eventual como um gênero, a norma de garantia como uma espécie sua ${ }^{23}$.

\footnotetext{
20 "Quando a ordem jurídica estabelece, por exemplo, que uma norma que não foi posta pelo órgão competente, ou foi posta por um indivíduo que nem sequer possui a qualidade de órgão, ou uma norma que tem um conteúdo que a Constituição exclui, devem ser consideradas nulas a priori e que, portanto, não é necessário qualquer ato para as anular, necessita determinar quem há de verificar a presença dos pressupostos desta nulidade; e, como esta verificação tem caráter constitutivo, como a nulidade da norma em questão é efeito desta verificação, como não pode ser juridicamente afirmada antes de realizada tal verificação, esta verificação significa, mesmo quando se opere na forma de uma declaração de nulidade, a anulação, com efeito retroativo, de uma norma até aí considerada válida". (KELSEN, 1998, p.307).

21 "Se o governo edita decretos [...] sob outras condições que não as determinadas pela Constituição, podem ser por isso responsabilizados e punidos os membros do governo que editaram o decreto. Este processo não tem de estar ligado com um processo destinado a anular à lei, se bem que o possa estar". (KELSEN, 1998, p. 304).

22 “[...] uma norma pertencente a uma ordem jurídica não pode ser nula mas apenas pode ser anulável. Mas esta anulabilidade prevista pela ordem jurídica pode ter diferentes graus. Uma norma jurídica em regra somente é anulada com efeitos para o futuro, por uma forma que os efeitos já produzidos que deixa para trás permaneçam intocados. Mas também pode ser anulada com efeito retroativo, por fora tal que os efeitos jurídicos que ela deixou atrás de si sejam destruídos". (KELSEN, 1998, p. 306).

23 "Na sua essência, a garantia repousa (embora não se esgote) num juízo de conformidade ou desconformidade perante a norma garantida; procura-se saber se um acto ou uma norma de grau inferior são conformes ou desconformes com uma norma de grau superior e, no caso de desconformes, procura-se inutilizá-las". (MIRANDA, 1996, p.212).
} 
A norma de garantia, ligada à norma de competência obtida da Constituição material, tem função certa, qual seja, invalidar a norma posta em desconformidade pelo legislador. Agora, sendo certo que em uma democracia a norma, lex legum, para criar normas gerais é abstratas é endereçada ao parlamento, devemos, então, buscar a quem deve ser dirigida a norma de garantia, que terá, assim, a função de invalidar a norma posta pelo legislativo quando em desconformidade com a Constituição.

\section{SEPARAÇÃO DAS FUNÇÕES}

De um ponto de vista jurídico, estritamente falando, as funções que podem ser desempenhadas são duas: de criação ou de aplicação da norma jurídica. Desse modo, quando se aponta serem três as funções ${ }^{24}$, o que se está a fazer não é outra coisa do que apartando a criação das normas em duas, a saber, por um lado, as abstratas, e, por outro, as concretas, com órgão diferentes para exercê-las ${ }^{25}$. Com efeito, por essa linha, juízes e legisladores ocupariam polos variegados, mas não devemos esquecer que a questão é meramente de grau, pois um estabelece a lei para todos e o outro a cria para o caso concreto, naquilo que é o processo de positivação do direito, ao longo da cadeia escalonada.

De toda sorte, de início, o embate era entre o criador da lei para todos, o legislativo, e o executor dessas leis, a administração pública, pois se via o legislativo sem meios — já que as forças policiais e armadas respondem, como regra, ao executivo - de fazer valer suas

\footnotetext{
24 "Existem em cada Estado três tipos de poder: o poder legislativo, o poder executivo das coisas que dependem do direito das gentes e o poder executivo daqueles que dependem do direito civil. Com o primeiro, o príncipe ou o magistrado cria leis por um tempo ou para sempre e corrige ou anula aquelas que foram feitas. Com o segundo, ele faz a paz ou a guerra, envia ou recebe embaixadas, instaura a segurança, previne invasões. Com o terceiro, ele castiga os crimes, ou julga as querelas entre os particulares. Chamaremos a este último poder de julgar e ao outro simplesmente poder executivo do Estado". (MONTESQUIEU, 2005, p.167-168).

${ }^{25}$ A oposição entre norma abstrata e norma concreta basta-nos para transmitir a ideia que aqui queremos, mas não é ela completa: "[...] em relação à hipótese normativa, a norma jurídica é "abstrata" ou "concreta", a depender da questão temporal, de já se ter ou não verificado no mundo seu conteúdo. Já quanto à consequência, a norma jurídica, a depender da conduta prescrita, que sempre é para o futuro, é uma "ocorrência" ou um "evento". No primeiro caso, ocorrência, há uma individualização, uma especificação; no segundo caso, evento, há notas que podem ser mais ou menos genéricas, sem haver uma exata precisão. Por fim, ainda na consequência normativa, há o sujeito que deve realizar a conduta (ação ou omissão). Pode ser um indivíduo, representado por um nome próprio, particularizado, o que nos leva a denominar a norma jurídica de "individual", ou pode ser um sujeito indeterminado, mesmo que determinável de forma mais ou menos genérica, o que permite então falar de norma jurídica "geral". Poderemos agora combinar os resultados encontrados, tanto na hipótese como na consequência, o que nos permite falar em oito $\left(2^{3}\right)$ espécies de normas jurídicas. Assim, temos as normas jurídicas: 1) concreta, ocorrente e individual; 2) concreta, ocorrente e geral; 3) concreta, eventiva e individual; 4) concreta, eventiva e geral; 5) abstrata, ocorrente e individual; 6) abstrata, ocorrente e geral; 7) abstrata, eventiva e individual; e 8) abstrata, eventiva e geral". (COSTA, 2019, p. 63).
} 
disposições. E se estivéssemos no plano Constitucional, a garantia buscada era contra o chefe do executivo, para que não usurpasse a competência do parlamento e criasse ele próprio as normas jurídicas de alcance geral. Nesse ponto, a existência de um terceiro órgão para apreciar o exercício da competência não se mostra imprescindível, pois a Constituição pode, v.g., estabelecer que, em caso de conflito, a prevalência seja do parlamento, até porque não seria errado imaginar que uma outra figura, que não o executivo ou o legislativo, também sem meios de impor sua decisão - já que os instrumentos de coação continuariam a cargo do executivo —, não teria muito como contribuir para pôr fim à dissenção, podendo, na verdade, agravá-la ${ }^{26}$.

Quanto a esse terceiro, que não o executivo e o legislativo, ou seja, o judiciário, não se olvida que sua função, além de resolver as querelas entre os particulares, impedindo que rixas terminem em duelo, passou a ser vista cada vez mais como limitação à atuação do executivo contra os cidadãos, garantindo a eles a liberdade e a propriedade no caso concreto, até porque não seria prático levar uma reclamação particular diretamente ao legislativo. Aqui é que tem lugar frases como "ainda existem juízes em Berlim". Agora, nesses termos, a questão não provoca maiores danos à separação das funções, haja vista que a integridade do executivo fica garantida, sendo apenas freada em um ou outro caso particular. Claro que quando a questão não é a de abstenção, mas a ação do governo, o tema ganha complexidade, pois dar uma ordem para que o executivo cuide das pessoas, garantindo seus direitos, da barriga da mãe ao túmulo, não faz com que materialmente as coisas se concretizem, acabando, no mais, apenas determinando que se tire de outro para dar ao demandante, impedindo qualquer critério racional de distribuição do que é finito, mas essa é outra discussão, que não vem ao caso neste artigo.

O tema, todavia, passa a ser de difícil compreensão quando a garantia não é mais contra o executivo, mas contra o próprio órgão encarregado de fazer as leis. Com efeito, como as normas de competência da Constituição para pôr norma abstrata são endereçadas ao parlamento, seria ele e não qualquer outro quem poderia as descumprir. A Constituição, assim, precisa de um garantidor, ou seja, de quem aplique a norma de garantia, invalidando a norma posta pelo legislativo, para que tenha um mínimo de eficácia, para que o procedimento e o conteúdo das leis predefinidos sejam respeitados. E com isso passamos a precisar de um outro sujeito que não o próprio legislativo, haja vista que poderia ser comprometida a eficácia da

\footnotetext{
${ }^{26}$ Em sentido contrário, KELSEN (2003b, p. 275): "Uma vez que justamente os casos mais importantes de violação constitucional Parlamento e governo são partes litigantes, é recomendável convocar para a decisão da controvérsia uma terceira instância que esteja fora desse antagonismo e que não participe do exercício do poder que a Constituição divide essencialmente entre Parlamento e governo".
} 
Constituição se ele ficasse encarregado de verificar a correção de sua ação normativa ${ }^{27}$. Assim, o parlamento, de herói que se contrapunha ao voraz executivo, passa a vilão, aquele que não respeita a Constituição, a qual fica, então, a carecer de um guardião ${ }^{28}$.

\section{DECISÃO JUDICIAL}

Em sua formulação clássica, a decisão judicial não poderia ter outro caráter a não ser o de declarar a lei para o caso concreto, sendo que "[...] os juízes da nação são apenas [...] a boca que pronuncia as palavras da lei [...]”. (MONTESQUIEU, 2005, p. 175). Tal ideia tem como pano de fundo que, de nada valeria retirar o poder do monarca para entregá-lo ao parlamento, se os juízes pudessem julgar da forma como melhor lhes conviesse. Entretanto, não é possível atribuir ao ato de julgar, o qual culmina em uma norma concreta, um caráter meramente mecanicista, já que, no processo de positivação normativo, “[m]esmo uma ordem o mais pormenorizada possível tem de deixar àquele que a cumpre ou executa uma pluralidade de determinações a fazer”. (KELSEN, 1998, p. 388). Isso não impede, todavia, toda uma gama de tentativas de estabelecer formas de controle sobre as decisões judiciais para que elas, ao menos em aparência, não sejam arbitrárias e não se mostrem, mesmo que de fato o sejam, como um mero ato de vontade do julgador. Assim, as decisões judiciais não devem ser apenas postas, mas igualmente devem ser justificadas ${ }^{29}$.

Com isso, podemos dizer que, em seu sentido tradicional, a decisão judicial é justificada em forma de silogismo, na qual “[...] a argumentação poderia ser expressa simbolicamente como: (A) Em qualquer caso, se $p$, então $q$ / (B) No caso em questão $p$ / (C) $\square$, no caso em questão, q". (MACCORMICK, 2006, p. 29). Não é aqui, claro, o caso de discutirmos se toda decisão judicial pode ser assim justificada, por dedução, mas de frisamos que o ponto forte da separação das funções é que enquanto a atividade do legislador tem como

\footnotetext{
${ }^{27}$ Para os casos em que não há outro órgão para verificar a atuação do legislativo, KELSEN (1998, p. 302-303) formula a sua posição de que o constituinte pôs à disposição do parlamento, para criar normas abstratas, determinações alternativas, na medida que ele pode ou não seguir o procedimento ou o conteúdo predefinidos: "A Constituição contém uma regulamentação direta e uma regulamentação indireta da legiferação; e o órgão legislativo tem a possibilidade de opção entre as duas".

${ }_{28}$ "En la actualidad, el frente de la Justicia no se dirige ya contra un monarca, sino contra el Parlamento". (SCHMITT, 1998, p. 245). Ao que KELSEN (2003b, p. 247) rebate: "Como se hoje na Alemanha a questão da constitucionalidade da atividade que o governo, composto por presidente e ministros, desenvolve com base no art. 48, não fosse uma questão de vida ou morte para a Constituição de Weimar!".

${ }^{29}$ "Na justificação interna verifica-se se a decisão se segue logicamente das premissas que se expõem como fundamentação; o objeto da justificação externa é a correção destas premissas". (ALEXY, 2017, p. 214).
} 
produto uma norma abstrata, a do juiz resulta em uma norma concreta. Enquanto um, como regra, faz a lei para todos, outro, por seu turno, faz a lei para as partes.

Logo, em um primeiro momento, a decisão judicial deve poder determinar o que ocorreu no passado, e nisso entra em questão a teoria das provas, como a quem, e em que casos, cabe o ônus de provar, bem como temas como presunção e ficção. Entretanto, não precisamos ir tão longe, bastando firmar que a decisão judicial, em sua forma elementar, trata dos fatos. Agora, se estabelece o estado de coisas ocorrido no mundo, ou não ocorrido, igualmente cuida ela do direito, devendo determinar se há norma jurídica para sobre os fatos fazer incidir. Aí surgem temas como a analogia e a interpretação a contrario sensu. De todo o modo, o pontosíntese é que tudo está restrito ao caso, com a norma a ser produzida descrevendo uma concretude e prescrevendo uma conduta específica, para um sujeito individualizado.

Pode até ser o caso de que, uma vez identificada a norma jurídica a ser aplicada à situação, possa o julgador, a depender do direito positivo ${ }^{30}$, verificar se foi ela produzida de acordo com a norma de competência, o que, em alguns cenários, implica perquirir sobre sua constitucionalidade. Mas, quanto à essa possibilidade de investigação, pode questionar-se, no plano político, sua conveniência, haja vista que, quando em um contexto extremamente descentralizado, com muito juízes, a segurança jurídica corre sério o risco de ser maculada. De qualquer modo, o cotejo pelo julgador da correção do conteúdo e do procedimento para a elaboração da norma abstrata em relação à Constituição não altera a situação de que a sua apreciação se dá para uma conjuntura específica, não sendo, per se, estendida a todos.

\section{CONTROLE DE CONSTITUCIONALIDADE}

A expressão "decisão judicial”, do modo como geralmente é usada, diz respeito à expedição de uma norma concreta, a partir de um fato ocorrido no passado, para um determinado sujeito, com a prescrição de uma particularizada conduta. Por essa linha, nada fica mais longe de uma decisão judicial do que a ideia de um controle de constitucionalidade que

\footnotetext{
${ }^{30}$ As opções são: o direito positivo permite, proíbe ou obriga que o julgador verifique a correção da norma jurídica em razão da norma de competência presente na Constituição material, mas "[s]e a Constituição nada preceituar sobre a questão de saber quem há de fiscalizar a constitucionalidade das leis, os órgãos a quem a Constituição confere poder para aplicar as leis, especialmente os tribunais, portanto, são por isso mesmo tornados competentes para efetuar esse controle". (KELSEN, 1998, p. 301).
} 
invalide uma norma de forma erga omnes, com a apreciação ocorrendo em abstrato, sem qualquer caso concreto determinado ${ }^{31}$.

Logo, não vemos, por localizarem-se em pontos opostos, uma necessidade inconteste de que o órgão que aplica o direito ao caso concreto, ou seja, o judiciário - e que com isso cria normas concretas —, seja o mesmo que deva decidir sobre se uma norma abstrata foi produzida em conformidade com o procedimento e conteúdo prescritos pela Constituição e, em caso negativo, invalidá-la para todos, sem a presença de qualquer particular circunstância. Afinal, de um ponto de vista de uma teoria do direito que não confunde conceitos necessários para a sua exposição com o melhor conteúdo para a norma jurídica, o controle de constitucionalidade de uma norma abstrata, quando tomado em abstrato e para todos, tem apenas como pressuposto que o órgão a desempenhar tal função seja diferente do órgão que legislou. Isso porque, em não assim sendo, não havendo órgãos diferentes, a norma de competência obtida da Constituição material pode ficar com sua eficácia comprometida, tornando-se mera recomendação ao parlamento $^{32}$.

E é em face de um mínimo de eficácia que se fala, para a Constituição, de um zelote, um fautor, um defensor, um guardião ou mesmo, porque não?, um campeão, que impute as consequências pela desconformidade da norma de competência, alcançando todos, mesmo que na ausência de um caso concreto. Assim, nada impede que o guardião da Constituição seja o presidente de uma República em um regime presidencialista, o que geralmente acontece, apesar de nem sempre nos darmos conta disso, como no caso do exercício de veto por inconstitucionalidade. Também poderíamos imaginar um poder moderador, pouvoir neutre, que pode ser tanto um monarca como um presidente, ambos em um regime parlamentarista, com funções bem delimitadas para o chanceler, ou o primeiro ministro ${ }^{33}$. Nesse ponto, o controle de

\footnotetext{
${ }^{31}$ Não podemos negar que, a depender do prisma, o controle de constitucionalidade também é uma análise de conduta ocorrida no passado, para imputar a ela uma consequência jurídica: "Tanto se um tribunal civil decide sobre a validade de um testamento ou contrato ou declara inconstitucional um decreto para não aplica-lo no caso concreto, ou se um tribunal constitucional qualifica uma lei como inconstitucional, em todos esses casos é o suporte fático da produção de um norma que é subsumido à norma que o regula e que é reconhecido como conforme ou contrário a ela". (KELSEN, 2003b, p. 247).

32 "Uma Constituição em que falte a garantia da anulabilidade dos atos inconstitucionais não é plenamente obrigatória, no sentido técnico". (KELSEN, 2003a, p. 179).

${ }^{33}$ Quando SCHMITT (1998, p. 250) defende ser o presidente o guardião da Constituição, devemos ter em conta que além dele, na Alemanha de então, tal qual na de hoje, havia ainda a figura do chanceler, em um regime parlamentarista. Com isso, para o teórico da exceção, o presidente estaria acima dos debates parlamentares e teria, igualmente, a legitimidade do voto popular: "Que el Presidente del Reich sea el protector de la Constitución corresponde también [...] al principio democrático sobre el cual descansa la Constitución de Weimar". Ao que KELSEN (2003b, p. 287) rebate: "Declarar o presidente do Reich como único guardião da Constituição contraria as mais claras disposições da Constituição do Reich".
} 
constitucionalidade das leis far-se-ia apenas para poucos casos, de forma moderada, respeitando, ao máximo, a autonomia do parlamento. Por esse mecanismo, não seria possível questionar a validade de toda norma jurídica posta pelo legislativo, com a alegação de que se vive em um "mar de inconstitucionalidade", pois caberia ao poder moderador escolher os casos em que sua atuação se faria necessária ${ }^{34}$. E poderíamos, ainda, considerar um "parlamento especial" para apreciar as ações normativas do "parlamento ordinário", como nos casos de uma câmara alta. Todas essas opções, de um ponto de vista de uma teoria do direito, seriam válidas, pois um órgão exerceria a função prescrita em norma de competência e outro disporia sobre a norma eventual, que garante a Constituição, invalidando a norma posta em desconformidade, mesmo que sem um caso concreto a ser apreciado. Entretanto, há ainda uma outra opção, a que granjeou a simpatia do meridiano de Greenwich do direito, de HANS KELSEN: o tribunal constitucional.

Quando se diz que a função do jurista é ensinar, apenas podemos aplaudir. Contudo, não podemos permitir que o jurista se torne o destinatário das normas jurídicas, para, então, interpretá-las para os demais cidadãos, que, segundo essa ótica, não teriam condição de isso fazer sozinhos. Tal situação configuraria uma usurpação das funções do parlamento, pois nela tudo teria de ser filtrado pelos jurisconsultos, quando muito bem se poderia abrir uma brecha entre o conteúdo da norma e a interpretação doutrinária, a qual se apresentaria como a correta, a verdadeira. Contra isso, nunca é demais repetir o óbvio, doutrinador não é eleito, doutrinador não tem voto, e não pode fazer as leis, mesmo que sob a roupagem da interpretação.

A doutrina se apoderando das funções do parlamento é um dos riscos que se tem, outro, muito mais agudo, com cores muito mais vivas, é quando o esvaziamento da atividade do parlamento vem por meio de um tribunal constitucional formado por pessoas de "notório saber jurídico", pois agora não estamos mais no ingênuo campo do docere, mas da vinculação, com imputação de consequências. Um tribunal de notáveis se, por um lado, pode exercer a função de garantidor da Constituição, também pode, por outro, converter-se em uma ameaça ao parlamento e, por conseguinte, à própria soberania popular ${ }^{35}$. Principalmente nos casos em que

\footnotetext{
34 "Respecto de la teoría del poder neutral, esta posición reviste particular interés, porque la función peculiar del tercero neutral no consiste en una actividad continua, imperante y reglamentadora, sino fundamentalmente en una actuación mediadora, tutelar y reguladora, que sólo en casos de necesidad se produce activamente, porque no debe competir con los demás poderes realizando una expansión del poder propio, y aun en su ejercicio debe ser, por naturaleza, normalmente serena y cauta". (SCHMITT, 1998, p. 220).

35 "A revolução americana eclodiu. O dogma da soberania popular saiu da comuna e apoderou-se do poder; todas as classes se comprometam por sua causa; combateu-se e triunfou-se em seu nome; tornou-se a lei das leis". (TOCQUEVILLE, 1979, p. 199). Assim, a soberania popular é a pedra de toque da democracia. Agora, se ela não
} 
há uma gama enorme de sujeitos aptos para questionar diretamente neste Tribunal a constitucionalidade das leis, e, ao lado disso, tal Constituição, ao regular o conteúdo do que que pode ser criado, fá-lo por meio de termos vagos e ambíguos, tudo sendo agravado, ainda, pela possibilidade de se exercer o controle em qualquer época ${ }^{36}$. Com efeito, Constituições que fazem uso extensos de termos valorativos, altamente controversos quando se faz necessário precisá-los, produzem muito mais do que amarrar o legislador no exercício da norma de competência, mas promovem, de fato, um esvaziamento das funções do parlamento. E mesmo KELSEN (2003, p. 251), defensor de um tribunal constitucional, não olvidou disso, afirmando que “[o] caráter político da jurisdição é tanto mais forte quanto mais amplo for o poder discricionário que a legislação, generalizante por sua própria natureza, lhe deve necessariamente ceder".

Um tribunal constitucional sem votos, de toda forma, perante a ideia máxima de democracia, pode cair bem para a apreciação de uma Constituição-pai, austera e direta, mas começa a fazer sombra ao parlamento quando o texto constitucional em questão melhor se enquadra naquilo que é denominado de Constituição-mãe. Isso porque, uma Constituição que estabelece a um órgão formado de múltiplos membros um procedimento para fazer as leis, com poucas restrições de conteúdo, de cunho negativo, é bem diferente de uma que crie vários procedimentos, a depender do caso, ao lado de numerosas especificações sobre o conteúdo, quer positivas quer negativas. No primeiro caso, a margem de manobra é pequena para a invalidação das leis; por sua vez, na segunda situação, parece-nos que o céu é o limite ${ }^{37}$.

Tribunais constitucionais - cujos membros se veem no papel de juristas, pessoas de notório saber, e não como representantes da população —, na ausência de um caso concreto,

pode ser exercida diretamente, precisando para se expressar, de um parlamento, é uma coisa; outra, totalmente diferente, é que as decisões mais importantes de um Estado caibam a um órgão sem voto.

36 “[...] seria bom, no interesse da segurança jurídica, encerrar a anulação, em particular das normas gerais e principalmente das leis e dos tratados internacionais, num prazo fixado pela Constituição, por exemplo, três a cinco anos a partir da entrada em vigor da norma a anular". (KELSEN, 2003a, p.170).

${ }^{37}$ Quando KELSEN (2003a, p. 153) se pôs a favor do tribunal constitucional, tinha em mente uma Constituição comedida em suas disposições: "A anulação de uma lei se produz essencialmente como aplicação das normas da Constituição. A livre criação que caracteriza a legislação está aqui quase completamente ausente. Enquanto o legislador só está preso pela Constituição no que concerne a seu procedimento — e, de forma totalmente excepcional, no que concerne ao conteúdo das leis que deve editar, e mesmo assim, apenas por princípios ou diretivas gerais - , a atividade do legislador negativo, da jurisdição constitucional, é absolutamente determinada pela Constituição". Assim, "[...] as normas constitucionais a serem aplicadas por um tribunal constitucional, sobretudo as que definem o conteúdo de leis futuras [...] não devem ser formuladas em termos demasiado gerais, nem devem operar com chavões vagos como 'liberdade', 'igualdade', 'justiça', etc. Do contrário existe o perigo de uma transferência de poder — não previsto pela Constituição e altamente inoportuno — do Parlamento para uma instância externa a ele [...]". (KELSEN, 2003b, p. 263). 
encarregados de tomar decisões sobre a constitucionalidade de normas abstratas, com efeito para todos, quando a Constituição é rica em termos cujos significados são altamente fluídos, com cada um podendo ter um para chamar de seu, é abrir as portas para se solapar a vontade popular que é - bem ou mal, é o melhor que temos - representada por meio do parlamento. Desse modo,

[...] não é impossível que um tribunal constitucional chamado a se pronunciar sobre a constitucionalidade de uma lei anule-a por ser injusta, sendo a justiça um princípio constitucional que ele deve por conseguinte aplicar. Mas nesse caso a força do tribunal seria tal, que deveria ser considerada simplesmente insuportável. [...]. É claro que a Constituição não entendeu, empregando uma palavra tão imprecisa e equívoca quanto a de justiça, ou qualquer outra semelhante, fazer que a sorte de qualquer lei votada pelo Parlamento dependesse da boa vontade de um colégio composto de uma maneira mais ou menos arbitrária do ponto de vista político, como o tribunal constitucional. (KELSEN, 2003a, p. 169).

E é nesse ponto que aquilo que ficou conhecido como o grande embate sobre a melhor forma de controle da constitucionalidade das leis, a disputa entre KELSEN e SCHMITT, dissipa-se. Um tribunal supremo que - fundamentado no bom, no belo e no justo - invalida leis votadas pelo parlamento, com efeito, pode pôr a perder a própria democracia.

Assim, proferidas há quase 100 anos, podem soar muito atuais as palavras de SCHMITT (1998, p. 245):

\footnotetext{
Ningún formalismo judicial podría encubrir el hecho de que semejante Tribunal de Justicia Política o Constitucional viniera a ser una instancia política suprema con atribuciones para formular preceptos constitucionales. Esto significaría algo apenas imaginable desde el punto de vista democrático: trasladar tales funciones a la aristocracia de la toga.
}

\section{CONCLUSÃO}

Podemos parafrasear o grande WINSTON CHURCHILL e dizer que entregar o controle constitucional das leis a um tribunal cujos membros não são eleitos pelos cidadãos seria o pior modo de garantir a Constituição, com exceção de todos os demais. Sendo assim, este artigo não teve por escopo se opor a que as invalidações das normas jurídicas abstratas, lastreadas diretamente na Constituição, sejam feitas por um tribunal constitucional. O que se pretendeu foi apenas chamar a atenção para que, se a justificação de tais decisões fundarem-se em termos com alta carga axiológica, cujos significados são extremamente controversos, então 
há sério risco de que se esteja, no fundo, substituindo o parlamento por um conselho de notáveis.

\section{REFERÊNCIAS BIBLIOGRÁFICAS}

ALEXY, Robert. Conceito e validade do direito. Tradução de: Gercélia Batista de Oliveira Mendes. São Paulo: WMF Martins Fontes, 2009.

- Teoria da argumentação jurídica: a teoria do discurso racional como teoria da fundamentação jurídica. Tradução de: Zilda Hutchinson Schild Silva. Rio de janeiro: Forense, 2017.

BOBBIO, Norberto. Teoria do ordenamento jurídico. Tradução de: Maria Celeste C. J. Santos. 10.ed. Brasília: Universidade de Brasília, 1999.

COSSIO, Carlos. Teoría de la verdad jurídica. Buenos Aires: El foro, 2007.

COSTA, Valterlei A. da. Ensaio para uma teoria trilógica do tributo: um estudo normativo sobre tributação, competência e lançamento. 2019. 248f. Dissertação (Mestrado em Direito) UFPR, Curitiba.

CUNHA, Sérgio Sérvulo da. Introdução à edição brasileira. In: KELSEN, Hans. Jurisdição constitucional. Tradução de: Alexandre Krug (alemão), Eduardo Brandão (italiano) e Maria Ermantina Galvão (francês). São Paulo: Martins Fontes, 2003, p. VII-XVIII.

DAHL, Robert A. Poliarquia. Tradução de: Celso Mauro Paciornik. São Paulo: EdUSP, 2015. GARCÍA, Pedro de Veja. Prologo. In: SCHMITT, Carl. La defesa de la Constitución. Traducción de: Manuel Sanchez Sarto. 2.ed. Madrid: Tecnos, 1998, p. 11-24.

HAMILTON, Alexandre; MADISON, Hamilton; JAY, John. O federalista. Tradução de: Leônidas Gontijo de Carvalho, A. Della Nina, J.A.G. Albuquerque e Francisco C. Weffort. 2.ed. São Paulo: Abril Cultural, 1979.

HESSE, Konrad. A força normativa da Constituição. Tradução de: Gilmar Ferreira Mendes. Porto Alegre/RS: Sérgio Antonio Fabris, 1991.

HUME, David. Tratado da natureza humana: uma tentativa de introduzir o método experimental de raciocínio nos assuntos morais. Tradução de: Débora Danowski. 2.ed. São Paulo: UNESP, 2009.

KELSEN, Hans. A garantia jurisdicional da Constituição. In: ___ Jurisdição constitucional. Tradução de: Alexandre Krug. São Paulo: Martins Fontes, 2003a, p. 123-186. 
Quem deve ser o guardião da Constituição. In: Jurisdição constitucional.

Tradução de: Maria Ermantina Galvão. São Paulo: Martins Fontes, 2003b, p. 239-298.

Teoria geral das normas. Tradução de: José Florentino Duarte. Porto Alegre: Sérgio A. Fabris, Editor, 1986.

. Teoria geral do direito e do estado. Tradução de: Luís Carlos Borges. 4.ed. São Paulo: Martins Fontes, 2005.

Teoria pura do direito. Tradução de: João Baptista Machado. 6.ed. São Paulo: Martins Fontes, 1998 (2.ed., 1960).

LASSALLE, Ferdinand. O que é uma Constituição?. [S.t.]. Leme/SP: CL EDIJUR, 2016.

MACCORMICK, Neil. Argumentação jurídica e teoria do direito. Tradução de: Waldéa Barcellos. São Paulo: Martins Fontes, 2006.

MIRANDA, Jorge. Contributo para uma teoria da inconstitucionalidade. [S.1.]: Coimbra Editora, 1996.

MONTESQUIEU. O espírito das leis. Tradução de: Cristina Murachco. 3.ed. São Paulo: Martins Fontes, 2005.

MORESO, José Juan. Normas jurídicas y estructura del derecho. México: Distribuciones Fontamara, 1997.

ROSS, Alf. Direito e justiça. Tradução de: Edson Bini. Bauru, SP: Edipro, 2003.

SCHMITT, Carl. La defesa de la Constitución. Traducción de: Manuel Sanchez Sarto. 2.ed. Madrid: Tecnos, 1998.

TOCQUEVIlle, Alexi de. A democracia na América. Tradução de: J.A.G. Albuquerque. 2.ed. São Paulo: Abril Cultural, 1979 (Os Pensadores).

VILANOVA, Lourival. As estruturas lógicas e o sistema de direito positivo. 3.ed. São Paulo: Noeses, 2005.

. Teoria jurídica da revolução (anotações à margem de Kelsen). Revista brasileira de estudos políticos, Belo Horizonte: UFMG, v. 52, p. 59-103, 1981.

WALTER, Robert. A teoria pura do direito. In: KELSEN, Hans. Teoria pura do direito. Tradução de: J. Cretella Jr. e Agnes Cretella. 9.ed. São Paulo: Revista dos Tribunais, 2013 (1.ed. 1934).

WRIGHT, Georg Henrik von. Norma y acción: una investigación lógica. Traducción de: Pedro Garcia Ferrero. Madrid: Editorial Tecnos, 1970. 